\title{
Effects of exercise on gut peptides, energy intake and appetite
}

\author{
Catia Martins, Linda M Morgan, Stephen $\mathbf{R}$ Bloom $^{\mathbf{1}}$ and $\mathbf{M}$ Denise Robertson \\ School of Biomedical and Molecular Sciences, University of Surrey, Guildford GU2 7XH, UK \\ ${ }^{1}$ Department of Metabolic Medicine, Hammersmith Hospital, Imperial College, London W12 ONN, UK \\ (Requests for offprints should be addressed to M D Robertson; Email: m.robertson@surrey.ac.uk)
}

\begin{abstract}
This study investigated the acute effects of exercise on the postprandial levels of appetite-related hormones and metabolites, energy intake (EI) and subjective measures of appetite. Ghrelin, polypeptide YY (PYY), glucagon-like peptide-1 (GLP-1) and pancreatic polypeptide (PP) were measured in the fasting state and postprandially in 12 healthy, normalweight volunteers (six males and six females) using a randomised crossover design. One hour after a standardised breakfast, subjects either cycled for $60 \mathrm{~min}$ at $65 \%$ of their maximal heart rate or rested. Subjective appetite was assessed throughout the study using visual analogue scales and subsequent EI at a buffet meal was measured at the end (3-h post-breakfast and 1-h post-exercise). Exercise significantly increased mean PYY, GLP-1 and PP levels, and this effect was maintained during the post-exercise period for GLP-1 and PP. No significant effect of exercise was observed on
\end{abstract}

postprandial levels of ghrelin. During the exercise period, hunger scores were significantly decreased; however, this effect disappeared in the post-exercise period. Exercise significantly increased subsequent absolute EI, but produced a significant decrease in relative EI after accounting for the energy expended during exercise. Hunger scores and PYY, GLP-1 and PP levels showed an inverse temporal pattern during the 1-h exercise/control intervention. In conclusion, acute exercise, of moderate intensity, temporarily decreased hunger sensations and was able to produce a short-term negative energy balance. This impact on appetite and subsequent energy homeostasis was not explained by changes in postprandial levels of ghrelin; however, 'exercise-induced anorexia' may potentially be linked to increased PYY, GLP-1 and PP levels.

Journal of Endocrinology (2007) 193, 251-258

\section{Introduction}

Obesity has become a global epidemic in developed countries (World Health Organization 2003) and UK is no exception with an almost threefold increase in obesity prevalence in the last two decades and present numbers indicating that over $60 \%$ of the population are overweight (National Audit Office 2001). This picture is undeniably linked to a decrease in physical activity (PA) over the past few decades, driven by dramatic changes in lifestyle (Varo et al. 2003, World Health Organization 2003).

Although the role of $\mathrm{PA}$ in preventing weight gain is widely accepted (Haapanen et al. 1997, Martinez-Gonzalez et al. 1999), its impact on weight loss in the absence of energy restriction seems to be only modest (Miller et al. 1997). The ability of exercise to create a negative energy balance (EB) relies not only directly on its impact on energy expenditure (EE), but also indirectly on its potential to modulate energy intake (EI) (King et al. 1997b). It has been suggested that the relative inefficacy of exercise on weight loss may originate from the energy deficit created by exercise being partially compensated for by an increase in EI (Blundell \& King 1999).

Even though most studies show no impact of acute exercise on appetite (King et al. 1996, Imbeault et al. 1997, Hubert et al. 1998) or subsequent EI (King et al. 1996, 1997a, Imbeault et al. 1997, Hubert et al. 1998, Blundell \& King 1999), this is a rather controversial area (Blundell \& King 1999).

Depending on the time frame of the response, different mechanisms operate in the complex system that regulates appetite and EB: long-term signals including leptin and insulin, intermediate signals including post-absorptive signals associated with macronutrient oxidation and, finally, shortterm mechanisms involving post-ingestive signals including the gut peptides ghrelin, cholecystokinin (CKK), peptide YY (PYY), glucagon-like peptide-1 (GLP-1) and pancreatic polypeptide (PP) (Blundell 1991, King et al. 1997b). These metabolic and endocrine signals are then received and processed by specific areas in the hypothalamus and brainstem, resulting in a co-ordinated response targeting both EI and EE (Neary et al. 2004). As exercise is a major determinant in the $\mathrm{EB}$ equation, it is, therefore, of extreme importance to determine how these appetite-related hormones respond to exercise. However, research in this area is rather limited (Sullivan et al. 1984, Greenberg et al. 1986, Bailey et al. 2001, O'Connor et al. 2006). The purpose of this study was, therefore, to investigate the effects of an acute period of moderate intensity exercise, when performed in the fed-state, on postprandial levels of ghrelin, PYY, GLP-1 and $\mathrm{PP}$ in normal-weight subjects and to correlate potential 
alterations with changes in subjective feelings of appetite/ satiety and prospective food intake at a subsequent meal.

\section{Material and Methods}

\section{Subjects}

Twelve healthy volunteers (six males and six females) not currently dieting to lose weight were recruited for this study. Their mean age was $25 \cdot 9 \pm 4 \cdot 6$ years and mean scores for restrained, external and emotional eating based on the Dutch Eating Behaviour Questionnaire (DEBQ; van Strien et al. 1986) were $2 \cdot 4 \pm 0 \cdot 8,2 \cdot 7 \pm 0 \cdot 6$ and $2 \cdot 2 \pm 0 \cdot 6$ respectively. Mean body mass index was $22 \cdot 0 \pm 3 \cdot 2 \mathrm{~kg} / \mathrm{m}^{2}$.

The exclusion criteria were as follows: a score of more than 3.5 in the restrained scale of the DEBQ, history of coronary heart disease, type 1 or type 2 diabetes, anaemia, gout, depression or other psychological disorders, eating disorders, drug or alcohol abuse within the last 2 years, current medication known to affect appetite or induce weight loss and hypertension. Smokers and those with a highly active lifestyle (performing more than $1 \mathrm{~h}$ of moderate to intense exercise per day, on every day of the week), based on a 3 months exercise history, were also excluded. The experimental protocol was approved by the University of Surrey Ethics Committee and subjects gave written informed consent.

\section{Study protocol}

Subjective appetite sensations, EI and postprandial levels of hormones and metabolites in response to rest and exercise were investigated using a randomised crossover design. Subjects acted as their own controls and were assigned to the two experimental conditions (resting and exercise), 1 week apart, in a counter-balanced order.

To reduce the inherent variability, for $24 \mathrm{~h}$ prior to each investigation, subjects were instructed to refrain from moderate to heavy exercise and from consuming alcohol. They were required to complete $24-\mathrm{h}$ dietary records, which were analysed for energy and macronutrients using WinDiets (Robert Gordons University, Aberdeen, UK). Participants were also provided with a standardised evening meal (pasta ready meal: $521 \mathrm{kcal}, 22 \mathrm{~g}$ protein, $26 \mathrm{~g}$ fat and $50.7 \mathrm{~g}$ carbohydrates) and asked to eat it at around $2000 \mathrm{~h}$ on the day preceding each of the study days.

On each of the two study days, subjects arrived in a fasted state at the clinical investigation unit (CIU) at $\sim 0800 \mathrm{~h}$. An i.v. cannula was inserted into an antecubital vein and two fasting blood samples were taken $(-30$ and $0 \mathrm{~min})$. Serial blood samples $(20 \mathrm{ml})$ were then taken at regular intervals for the following $3 \mathrm{~h}$.

Subjects consumed a standard breakfast at time, $t=0 \mathrm{~h}$ (hot chocolate drink: $500 \mathrm{kcal}, 18.9 \mathrm{~g}$ protein, $21.4 \mathrm{~g}$ fat and $59.4 \mathrm{~g}$ carbohydrate; this meal has been used by us in the previous studies; Robertson et al. 2003) and were randomly allocated to a resting or exercise intervention which began at $t=1 \mathrm{~h}$. During the resting condition, participants remained seated, whilst allowed to read/write quietly. During the exercise condition, participants cycled on a cycle ergometer at $65 \%$ of their age estimated maximal heart rate (maxHR) for 60 min. Participants were provided with water available ad libitum throughout the study.

Visual analogue scores (VAS) for hunger, fullness and prospective food consumption were completed after each blood sample, as described previously (Hill et al. 1987, Flint et al. 2000). After the resting/exercise intervention $(t=$ 120-180 $\mathrm{min}$ ), participants stayed in the CIU, but were free to write/read quietly. One hour after the end of the exercise/ resting intervention ( $t=180 \mathrm{~min}$ ), participants were placed at individual booths, presented with a buffet test meal and instructed to eat as much as or as little as they wanted until satisfied.

\section{Exercise bout}

The exercise intervention consisted of intermittent cycling on a cycle ergometer at $65 \%$ of each subject's estimated maxHR for $\sim 60 \mathrm{~min}(2 \mathrm{~min}$ warming up $+17 \mathrm{~min}$ exercise $+3 \mathrm{~min}$ break $+17 \mathrm{~min}$ exercise $+3 \mathrm{~min}$ break $+17 \mathrm{~min}$ exercise + 2 min cooling down). HR was measured continuously using a HR monitor (Polar F1 - Polar Electro Oy, Kempele, Finland). Average heart rate during the $60-$ min cycling was $129 \pm 6 \mathrm{bpm}$, corresponding to $66 \cdot 4 \pm 2 \cdot 5 \%$ of maxHR.

The energy expended during the exercise and resting sessions (180 min) was calculated using metabolic equivalents (MET) as previously described (Ainsworth et al. 2000).

\section{Buffet meal}

The buffet test meal consisted of a standardised buffet available ad libitum, in excess of expected consumption $(4100 \mathrm{kcal}, 85 \mathrm{~g}$ protein, $250 \mathrm{~g}$ fat and $373 \mathrm{~g}$ carbohydrates), with a variety of lunch-type foods (sandwiches, salad, fruit, cake, biscuits, crisps, yogurt, mayonnaise and mustard). The choice of a buffet instead of a homogeneous meal allowed the measurement of not only total energy, but also macronutrient selection.

In an attempt to avoid over- or under-consumption due to the presence of highly desirable foods or, conversely, no palatable foods, participants were asked before the start of the study to rank different food items by order of preference and eliminate those that they would not eat. Based on this questionnaire, the buffets were made up of the second or second and third preferences rated by each subject (Rogers 1993).

The buffet foods were weighed/counted before participants sat down to the meal and reweighed/recounted after each subject had finished eating, and energy and macronutrient intake calculated.

\section{Hormone and metabolites measurement}

Venous blood was collected into potassium-oxalate tubes for analysis of glucose, lithium heparin tubes for lipids and insulin, 

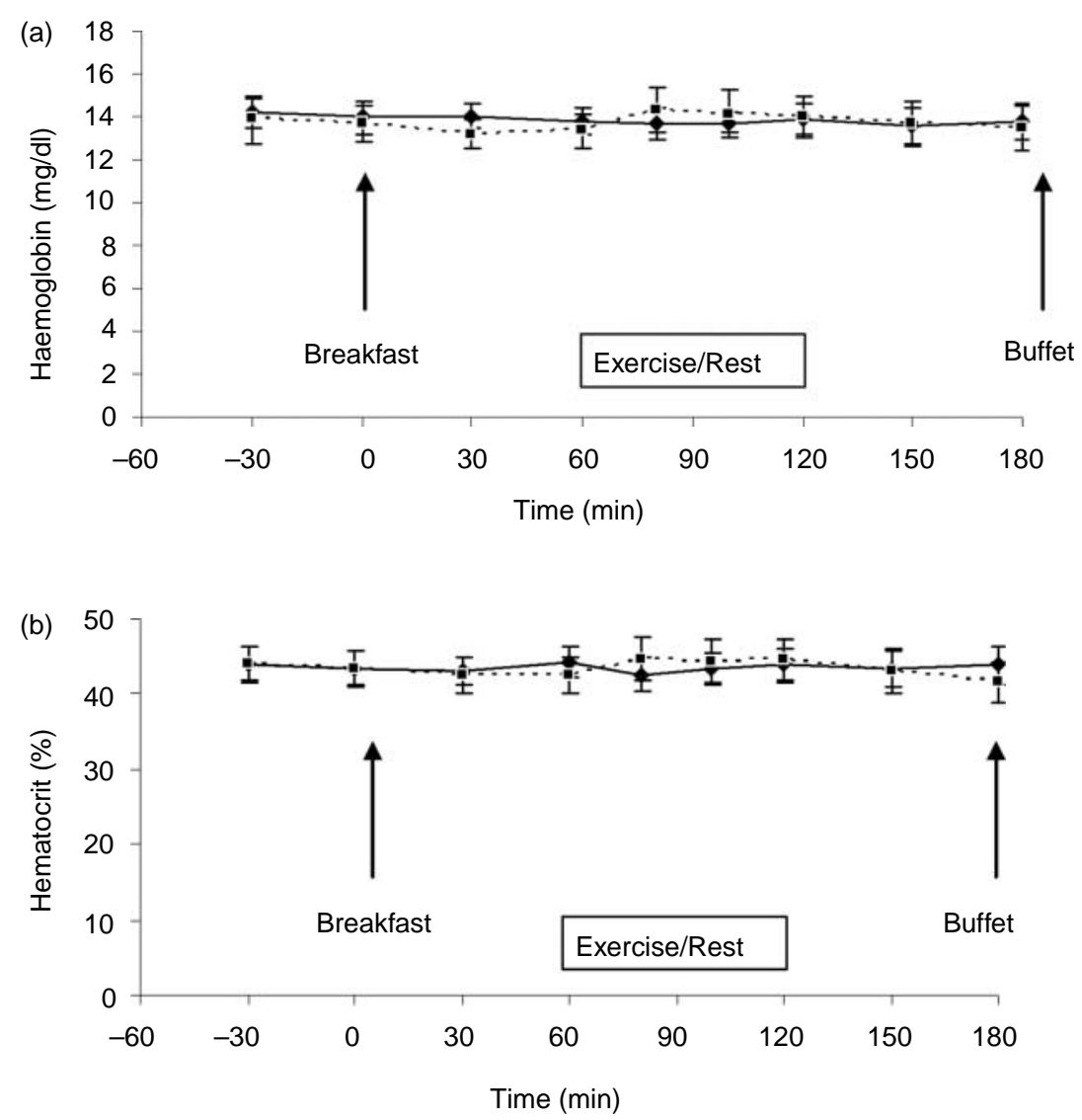

Figure 1 (a) Haemoglobin levels (mg/dl) over time, $1 \mathrm{~h}$ after a $500 \mathrm{kcal}$ breakfast, during the exercise (*) and control $(\bullet)$ trials. Values represent means \pm s.E.M. for 12 subjects. Repeated measures ANOVA showed no significant main effects of time, condition or time $\times$ condition interaction. (b) Hematocrit (\%) over time, $1 \mathrm{~h}$ after a $500 \mathrm{kcal}$ breakfast, during the exercise ( $\bullet$ ) and control $(\bullet)$ trials. Values represent means \pm s.E.M. for 12 subjects. Repeated measures ANOVA showed no significant main effects of time, condition or time $\times$ condition interaction.

and potassium EDTA-coated tubes, containing $200 \mathrm{kIU}$ aprotinin/ml whole blood, for the measurement of gut peptides. Samples were then centrifuged at $1750 \mathrm{~g}$ for $10 \mathrm{~min}$ and the plasma stored at $-20{ }^{\circ} \mathrm{C}$. All samples were batch analysed at the end of the study to reduce interassay variability.

Plasma triacylglycerol (TAG) and non-esterified fatty acids (NEFA) were measured colorimetrically using an automated centrifugal analyser (Randox Space, Antrim, UK AlfaWasserMann) and glucose using an immobilised enzyme biosensor (YSI 2300 Stat Plus Glucose \& Lactate Analyzer). Total ghrelin, PYY, GLP-1, PP and insulin were quantified using established RIAs (Adrian et al. 1976, 1985, Hampton 1984, Kreymann et al. 1987, Patterson et al. 2005). The sensitivity of the assays was $2.5 \mathrm{pmol} / 1$ for insulin and PP, $17 \mathrm{pmol} / 1$ for ghrelin, $2 \mathrm{pmol} / 1$ for PYY and $1 \mathrm{pmol} / 1$ for GLP-1. All samples were assayed in duplicate and in one assay to eliminate the effects of interassay variation. The interassay coefficient of variation can then be removed. All metabolites and hormones assayed exhibited an intra-assay coefficient of variation of $<5$ and $10 \%$ respectively.

Hematocrit (Hct) was measured in duplicate with a microHct centrifuge and haemoglobin $(\mathrm{Hb})$ was measured using a co-oximeter (Instrumentation Laboratory, Warrington, UK).

\section{Statistical analysis and calculations}

Statistical analysis was carried out using SPSS version 11.0 (SPSS, Inc., Chicago, IL, USA). All the variables were checked regarding their normal distribution using the Shapiro-Wilk test and data expressed as means \pm s.E.M., unless otherwise stated.

Differences in fasting/postprandial levels of metabolites and hormones and appetite/hunger sensations between the two conditions (control and exercise) were assessed by a two-way repeated measure ANOVA using treatment and time as independent variables. Relative energy intake (REI) was 

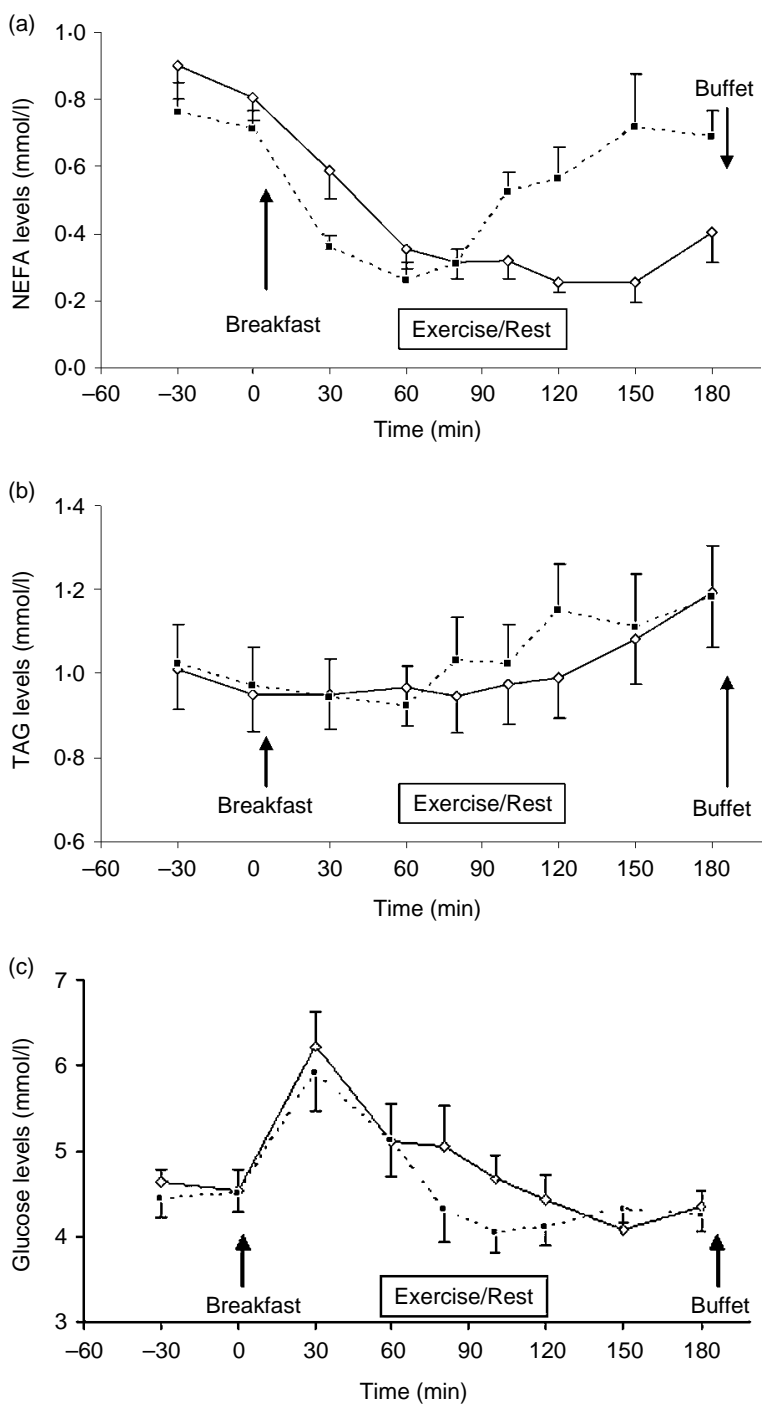

Figure 2 (a) Plasma NEFA concentrations ( $\mathrm{mmol} / \mathrm{l})$ over time, $1 \mathrm{~h}$ after a $500 \mathrm{kcal}$ breakfast, during the exercise $(\cdot)$ and control $(\diamond)$ trials. Values represent means \pm s.E.M. for 12 subjects. Repeated measures ANOVA showed no significant main effects of time or condition but a significant time $\times$ condition interaction $(P<0 \cdot 0001)$. (b) Plasma TAG concentrations $(\mathrm{mmol} / \mathrm{l})$ over time, $1 \mathrm{~h}$ after a $500 \mathrm{kcal}$ breakfast, during the exercise $(\cdot)$ and control $(\diamond)$ trials. Values represent means \pm S.E.M. for 12 subjects. Repeated measures ANOVA showed no significant main effects of time or condition but a significant time $\times$ condition interaction $(P=0 \cdot 011)$. (c) Plasma glucose concentrations $(\mathrm{mmol} / \mathrm{l})$ over time, $1 \mathrm{~h}$ after a $500 \mathrm{kcal}$ breakfast, during the exercise $(\bullet)$ and control $(\diamond)$ trials. Values represent means \pm S.E.M. for 12 subjects. Repeated measures ANOVA showed a significant effect of time $(P<0 \cdot 0001)$, but no significant effect of condition or condition $\times$ time interaction.

calculated by subtracting the estimated EE during the exercise and rest sessions $(180 \mathrm{~min}$ ) from their respective buffet EI. Differences in absolute and relative EI at the buffet lunch, as well as in the percentage of energy provided by each macronutrient, between the two experimental conditions were assessed using paired sample $t$-tests.
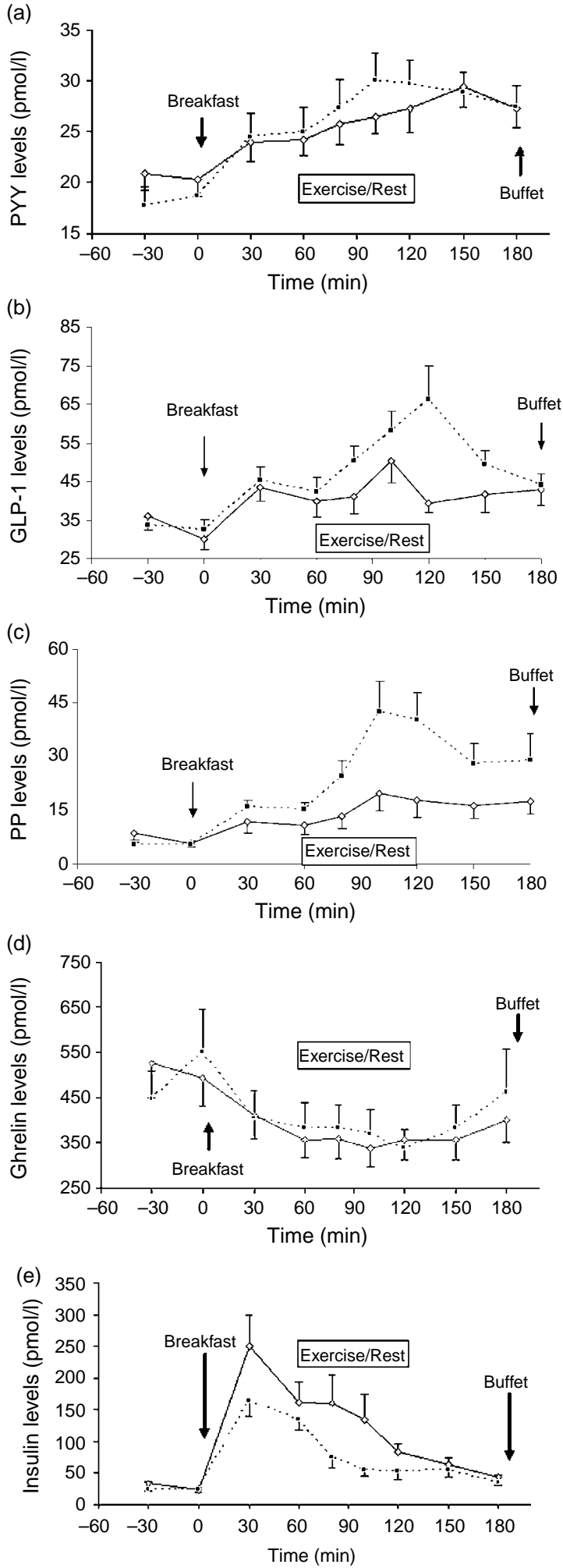

www.endocrinology-journals.org 
How hungry do you feel?

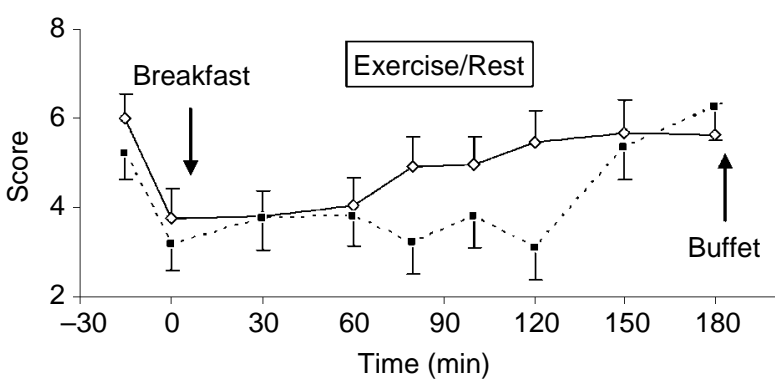

Figure 4 VAS scores for hunger over time during the exercise (-) and control $(\diamond)$ trials. Values represent means \pm s.E.M. for 12 subjects. Repeated measures ANOVA showed a significant effect of time $(P<$ $0 \cdot 0001)$ and a condition $\times$ time interaction $(P=0 \cdot 004)$.

\section{Results}

No significant differences between study legs were observed in energy or macronutrient intake in the $24 \mathrm{~h}$ prior to each trial.

\section{Plasma metabolites and hormones}

No significant changes in either Hct or $\mathrm{Hb}$ were observed over time during the exercise or the control leg (Fig. 1a and b). Therefore, as there was no evidence for haemoconcentration during the exercise leg of the study, all metabolites and hormones measured are expressed in pmol/1 plasma instead of all blood volume.

Mean plasma levels of NEFA $(P<0 \cdot 0001$; Fig. 2a) and TAG $(P=0 \cdot 011$; Fig. 2 b) became elevated during exercise, when compared with similar period of resting. Glucose plasma levels were not significantly affected by exercise

Figure 3 (a) Plasma PYY concentrations (pmol/L) over time, $1 \mathrm{~h}$ after a $500 \mathrm{kcal}$ breakfast, during the exercise ( $\bullet$ ) and control $(\diamond)$ trials. Values represent means \pm S.E.M. for 12 subjects. Repeated measures ANOVA showed a significant effect of time $(P<0 \cdot 0001)$ and a significant condition $\times$ time interaction $(P=0 \cdot 038)$. (b) Plasma GLP1 concentrations (pmol/l) over time, $1 \mathrm{~h}$ after a $500 \mathrm{kcal}$ breakfast, during the exercise $(\bullet)$ and control $(\diamond)$ trials. Values represent means \pm S.E.M. for 12 subjects. Repeated measures ANOVA showed a significant effect of time $(P<0 \cdot 0001)$, condition $(P=0 \cdot 011)$ and condition $\times$ time interaction $(P=0 \cdot 001)$. (c) Plasma PP concentrations (pmol/l) over time, $1 \mathrm{~h}$ after a $500 \mathrm{kcal}$ breakfast, during the exercise $(\bullet)$ and control $(\diamond)$ trials. Values represent means \pm s.E.M. for 12 subjects. Repeated measures ANOVA showed a significant effect of time $(P<0 \cdot 0001)$, condition $(P=0 \cdot 001)$ and a condition $\times$ time interaction $(P<0 \cdot 0001)$. (d) Plasma ghrelin concentrations ( $\mathrm{pmol} / \mathrm{l})$ over time, $1 \mathrm{~h}$ after a $500 \mathrm{kcal}$ breakfast, during the exercise $(\cdot)$ and control $(\diamond)$ trials. Values represent means \pm s.E.M. for 12 subjects. Repeated measures ANOVA showed a significant effect of time $(P<$ 0.0001), but no effect of condition or time $\times$ condition interaction. (e) Plasma insulin concentrations ( $\mathrm{pmol} / \mathrm{l})$ over time, $1 \mathrm{~h}$ after a $500 \mathrm{kcal}$ breakfast, during the exercise $(\bullet)$ and control $(\diamond)$ trials. Values represent means \pm s.E.M. for 12 subjects. Repeated measures ANOVA showed no significant effect of time, and a trend towards a significant effects of condition $(P=0.066)$ and time $\times$ condition interaction $(P=0 \cdot 069)$.
(Fig. 2c). Mean PYY, GLP-1 and PP levels were significantly increased $(P=0 \cdot 038,0 \cdot 011$ and $0 \cdot 001$ respectively) during the $1-\mathrm{h}$ exercise $(60-120 \mathrm{~min})$, and this increase was maintained during the post-exercise period for GLP-1 and PP (Fig. 3a-c). No significant effects were observed in ghrelin levels (Fig. 3d). Despite a tendency for lower insulin levels during the 1-h exercise intervention, when compared with a similar period of resting, they did not reach statistical significance $(P=0 \cdot 066$; Fig. 3e).

No significant differences were observed in the plasma levels of any of the hormones and the metabolites immediately before buffet lunch $(t=180 \mathrm{~min})$ between the two conditions, with the exception of NEFA levels that were significantly higher in the exercise when compared with the control leg $(0 \cdot 69 \pm 0 \cdot 28$ vs $0 \cdot 40 \pm 0 \cdot 31 \mathrm{mmol} / 1, P=0 \cdot 001)$.

An inverse temporal pattern was observed, during the 1-h exercise/control intervention, between hunger and motivation to eat scores and PYY, GLP-1 and PP levels.

Effects on self-reported appetite/satiety measures and subsequent food intake

Hunger scores ('How hungry do you feel?') were significantly decreased $(P=0 \cdot 004)$ during the 1 -h exercise period, but the effect was transient and disappeared postexercise (Fig. 4). No significant changes were observed in fullness ('How full do you feel?') or motivation to eat ('How much do you feel you can eat?') in response to exercise (data not shown). The VAS scores taken at $180 \mathrm{~min}$, immediately before the buffet meal, were not significantly different between the two conditions.

Absolute energy intake at the buffet meal was significantly higher in the exercise when compared with the control intervention $(P=0.04$ and 0.035 respectively), with no significant differences being observed in the percentage of energy provided by either protein, fat or carbohydrates (Table 1). When absolute EI was adjusted for the energy expended during each condition, there was a significantly lower REI following the exercise period when compared with control $(P=0 \cdot 038$; Table 1$)$.

Table 1 Absolute energy and macronutrient intake at the buffet lunch and 'relative' energy intake (REI) during the exercise and control trials. Values are means \pm s.D.

\section{Exercise}

Absolute

Energy (kcal)

Protein $(\%)$

Fat $(\%)$

Carbohydrates (\%)

REI (kcal)

EE (kcal)

$$
\begin{gathered}
913 \pm 363^{*} \\
14 \pm 2 \\
36 \pm 7 \\
51 \pm 6 \\
421 \pm 302^{*} \\
492 \pm 92^{*}
\end{gathered}
$$

Control

$$
\begin{gathered}
762 \pm 252^{*} \\
15 \pm 3 \\
33 \pm 6 \\
53 \pm 5 \\
565 \pm 226^{*} \\
197 \pm 37^{*}
\end{gathered}
$$

$\mathrm{EE}$, energy expenditure; REI, relative energy intake (El after accounting for $\mathrm{EE}$ ). Means sharing the same symbol denote significant differences between trials: $* P<0 \cdot 05$. 


\section{Discussion}

Our aim was to investigate whether acute exercise could affect the postprandial levels of ghrelin, PYY, GLP-1 and PP, thereby providing a potential mechanism for changes in appetite sensations and EI in response to exercise. For the first time, we have shown that an acute bout of moderate intensity exercise performed in the fed-state increases PYY, GLP-1 and PP plasma levels, in normal-weight subjects, with a concomitant reduction in self-reported hunger. The phenomenon of 'exercise-induced anorexia' although traditionally associated with intense exercise (King et al. 1994) has also been reported after moderate intensity exercise (Tsofliou et al. 2003), consistent with our findings.

One hour of moderate intensity exercise caused a significant increase in EI at the buffet meal. This is a rather surprising result since no significant differences in hunger scores or gut hormone concentrations immediately before food intake were observed between conditions. However, this apparent uncoupling between subjective feelings of hunger and food intake has been previously reported (Mattes 1990, Flint et al. 2000).

Surprisingly, once the energy expended during the 1-h exercise had been accounted for, a significant reduction in relative energy expenditure (REE) was observed, allowing the attainment of a short-term negative EB. We were able to reproduce this pattern. Even though the use of METs to estimate EE has some limitations, since it does not take into account subjects' fitness level or gender (two important predictors of EE), similar results were obtained when EE was estimated using an equation (Hiilloskorpi et al. 2003) specific for each gender which incorporates $\mathrm{HR}$, an accurate predictor of EE.

In response to feeding, PYY and GLP-1 are both secreted from endocrine L-cells of the distal ileum and colon (Bottcher et al. 1984) and PP, a member of the PP-fold peptide family, which also includes PYY and neuropeptide Y (NPY), is produced by endocrine type F-cells of the pancreatic islets (Adrian et al. 1976). These satiety hormones seem to inhibit food intake by altering central nervous system appetite circuits, within the arcuate nucleus of the hypothalamus or area postrema (Gutzwiller et al. 1999, Batterham \& Bloom 2003). However, the inhibitory effect of PP on food consumption seems to be indirectly regulated through vagal nerves in part by decreasing gastric emptying (Katsuura $e t$ al. 2002).

This is the first study to address the effects of exercise on PYY levels in humans. A single study has previously demonstrated that running had no impact on postprandial GLP-1 levels when compared with a similar period of rest (O'Connor et al. 2006). However, this study involved highintensity exercise and was performed in athletes. An increase in PP plasma levels has been reported, both in fasting (Hilsted et al. 1980, Sullivan et al. 1984) and in response to a meal (Greenberg et al. 1986), consistent with our results. However, the role of PP on subjective hunger and EI in response to acute exercise is a novel aspect of this study.

We have now demonstrated that acute exercise increases PYY, GLP-1 and PP plasma levels, although the effect was short-lived for PYY. Interestingly, hunger scores and the plasma levels of these gut peptides showed an inverse temporal pattern during the 1-h exercise/control intervention; while mean levels of these satiety hormones increased, theoretically inducing a higher satiety effect, hunger scores were suppressed. Although several mechanisms have been proposed to explain 'exercise-induced anorexia' (King et al. 1997b, Westerterp-Plantenga et al. 1997), the reason for this phenomenon remains unknown. It needs to be addressed whether the inverse relationship observed between hunger scores and the plasma levels of these gut peptides (PYY, GLP1 and PP) can be considered causal. A significant increase in the plasma levels of these gut peptides, together with a significant suppression in hunger scores (compared with infusion of saline) have been reported in studies where these hormones were infused to normal-weight healthy volunteers (Flint et al. 1998, Batterham et al. 2003, Degen et al. 2005). However, the satiety effects of these hormones are only seen at pharmacological rather than physiological levels. Even though the observed increase in PYY, GLP-1 and PP plasma levels with exercise was probably too small to have effects on hunger when considered in isolation, PYY and GLP-1 have already been shown to inhibit food intake additively when infused together (Neary et al. 2005) and the anorexic effects observed with PP infusion seem to be independent of changes in PYY, GLP-1 or indeed other gut peptides (Batterham et al. 2003). The concomitant increase in the plasma levels of these satiety peptides yields, therefore, a potential explanation for the phenomenon of 'exercise-induced anorexia'. However, the precise role of these gut peptides in this phenomenon can only be fully investigated when specific antagonists of these hormones, in humans, become available.

Ghrelin, in opposition, is the only peripheral hormone with orexigenic properties, and is probably involved in meal initiation (Cummings et al. 2001). Fasting ghrelin levels do not seem to respond to acute exercise, at least in normalweight subjects (Schmidt et al. 2004). A single study reported a significant change, in overweight women, but found no effect when the same volume of exercise was performed in the fed-state (Borer et al. 2005). We were able to reproduce this latter finding in normal-weight subjects, by showing no significant changes in postprandial ghrelin plasma levels with 1-h moderate intensity exercise.

Although we showed that exercise in the fed-state induces compensatory neuroendocrine reflexes needed for the regulation of metabolic fuels (Coyle 2000), with increases in both NEFA and TAG levels, we were not able to show a similar compensatory response regarding ghrelin, PYY, GLP-1 and PP, GI hormones involved in appetite regulation, which would defend the body against a negative EB. There is no evidence that acute exercise triggers physiological adaptations that would lead to an increase in hunger 
sensations or subsequent EI, with the exception of the Borer et al. (2005) study that was performed in overweight postmenopausal women. The significant increase in buffet EI observed with exercise (despite the attainment of a negative EB when REI was accounted for) was not explained by differences in hunger sensations or changes in any of the appetite-related hormones studied. We suggest that the increased EI in response to acute exercise may be the result of cognitive factors including attitudes and beliefs associated with exercise, such as 'food rewards for exercising' and the belief that 'exercise increases appetite' (King 1999).

Our findings that acute exercise, performed in the fed-state, significantly increases PYY, GLP-1 and PP levels but has no effect on ghrelin levels, together with the shortlived suppression of hunger and a significant reduction in REI, supports the hypothesis that acute exercise is able to produce a short-term negative $\mathrm{EB}$ and, if sustained in the long-term, may have an important role in weight maintenance. The phenomenon of 'exercise-induced anorexia' may be potentially linked to the increased PYY, GLP-1 and PP levels observed during exercise.

\section{Acknowledgements}

We thank Dr Shelagh Hampton, Natalie Bree, Michael Patterson and Sejal Patel for technical assistance, Dr John Wright for clinical assistance and all our volunteers for taking part in this study.

\section{Funding}

Catia Martins was supported by a $\mathrm{PhD}$ grant (SFRD/BD/16294/2004) from Fundação para a Ciência e Tecnologia (Portugal) under the 3rd European Union community support programme. The authors declare that there is no conflict of interest that would prejudice the impartiality of this scientific work.

\section{References}

Adrian TE, Bloom SR, Bryant MG, Polak JM, Heitz PH \& Barnes AJ 1976 Distribution and release of human pancreatic polypeptide. Gut 17 940-944.

Adrian TE, Ferri GL, Bacarese-Hamilton AJ, Fuessl HS, Polak JM \& Bloom SR 1985 Human distribution and release of a putative new hormone, peptide YY. Gastroenterology 89 1070-1077.

Ainsworth BE, Haskell WL, Whitt MC, Irwin ML, Swartz AM, Strath SJ, O'Brien WL, Bassett DR Jr, Schmitz KH, Emplaincourt PO et al. 2000 Compendium of physical activities: an update of activity codes and MET intensities. Medicine and Science in Sports and Exercise 32 S498-S516.

Bailey DM, Davies B, Castell LM, Newsholme EA \& Calam J 2001 Physical activity and normobaric hypoxia: independent modulators of peripheral cholecystokinin metabolism in man. Journal of Applied Physiology 90 105-113.

Batterham RL \& Bloom SR 2003 The gut hormone peptide YY regulates appetite. Annals of the New York Academy of Sciences 994 162-168.
Batterham RL, le Roux CW, Cohen MA, Park AJ, Ellis SM, Patterson M, Frost GS, Ghatei MA \& Bloom SR 2003 Pancreatic polypeptide reduces appetite and food intake in humans. Journal of Clinical Endocrinology and Metabolism 88 3989-3992.

Blundell JE 1991 The biology of appetite. Clinical and Applied Nutrition 121-31. Blundell JE \& King NA 1999 Physical activity and regulation of food intake: current evidence. Medicine and Science in Sports and Exercise 31 573-583.

Borer KT, Wuorinen E, Chao C \& Burant C 2005 Exercise energy expenditure is not consciously detected due to oro-gastric, non metabolic, basis of hunger sensation. Appetite 45 177-181.

Bottcher G, Sjolund K, Ekbad E, Hakanson R, Schwartz TW \& Sundler F 1984 Coexistence of peptide YY and glicentine immunoreactivity in endocrine cells of the gut. Regulatory Peptides 8 261-266.

Coyle EF 2000 Physical activity as a metabolic stressor. American Journal of Clinical Nutrition 72 512S-520S.

Cummings DE, Purnell JQ, Frayo RS, Schmidova K, Wisse BE \& Weigle DS 2001 A preprandial rise in plasma ghrelin levels suggests a role in meal initiation in humans. Diabetes 50 1714-1719.

Degen L, Oesch S, Casanova M, Graf S, Ketterer S, Drewe J \& Beglinger C 2005 Effect of peptide YY3-36 on food intake in humans. Gastroenterology 129 1430-1436.

Flint A, Raben A, Astrup A \& Holst JJ 1998 Glucagon-like peptide-1 promotes satiety and suppresses energy intake in humans. Journal of Clinical Investigation 101 515-520.

Flint A, Raben A, Blundell JE \& Astrup A 2000 Reproducibility, power and validity of visual analogue scales in assessment of appetite sensations in single test meal studies. International Journal of Obesity and Related Metabolic Disorders $2438-48$.

Greenberg GR, Marliss EB \& Zinman B 1986 Effects of exercise on the pancreatic polypeptide response to food in man. Hormone and Metabolic Research 18 194-196.

Gutzwiller JP, Goke B, Drewe J, Hildebrand P, Ketterer S, Handschin D, Winterhalder R, Conen D \& Beglinger C 1999 Glucagon-like peptide-1: a potent regulator of food intake in humans. Gut 44 81-86.

Haapanen N, Miilunpalo S, Pasanen M, Oja P \& Vuori I 1997 Association between leisure time physical activity and 10-year body mass change among working-aged men and women. International Journal of Obesity 21 288-296.

Hampton SM 1984 C-peptide of proinsulin: its diagnostic use and a possible physiological role. PhD Thesis, University of Surrey. Thesis/Dissertation.

Hiilloskorpi HK, Pasanen ME, Fogelhom MG, Laukkanen RM \& Manttari AT 2003 Use of heart rate to predict energy expenditure from low to high activity levels. International Journal of Sports Medicine 24 332-336.

Hill AJ, Leathwood PD \& Blundell JE 1987 Some evidence for short-term caloric compensation in normal weight human subjects: the effects of highand low-energy meals on hunger, food preference and food intake. Human Nutrition, Clinical Nutrition 41A 244-257.

Hilsted J, Galbo H, Sonne B, Schwartz T, Fahrenkrug J, Schaffalitzky de Muckadell OB, Lauritsen KB \& Tronier B 1980 Gastroenteropancreatic hormonal changes during exercise. American Journal of Physiology 239 613-640.

Hubert P, King NA \& Blundell JE 1998 Uncoupling the effects of energy expenditure and energy intake: appetite response to short-term energy deficit induced by meal omission and physical activity. Appetite 31 9-19.

Imbeault P, Saint-Pierre S, Almeras N \& Tremblay A 1997 Acute effects of exercise on energy intake and feeding behaviour. British Journal of Nutrition 77 511-521

Katsuura G, Asakawa A \& Inui A 2002 Roles of pancreatic polypeptide in regulation of food intake. Peptides 23 323-329.

King NA 1999 What processes are involved in the appetite response to moderate increases in exercise-induced energy expenditure? Proceedings of the Nutrition Society $\mathbf{5 8} 107-113$.

King NA, Burley VJ \& Blundell JE 1994 Exercise-induced suppression of appetite: effects on food intake and implications for energy balance. European Journal of Clinical Nutrition 48 715-724.

King NA, Snell L, Smith RD \& Blundell JE 1996 Effects of short-term exercise on appetite responses in unrestrained females. European Journal of Clinical Nutrition 50 663-667. 
King NA, Lluch A, Stubbs RJ \& Blundell JE 1997a High dose exercise does not increase hunger or energy intake in free living males. European Journal of Clinical Nutrition $\mathbf{5 1}$ 478-483.

King NA, Tremblay A \& Blundell JE $1997 b$ Effects of exercise on appetite control: implications for energy balance. Medicine and Science in Sports and Exercise 29 1076-1089.

Kreymann B, Ghatei MA, Williams G \& Bloom SR 1987 Glucagon-like peptide -1 7-36: a physiological incretin in man. Lancet 5 1300-1304.

Martinez-Gonzalez MA, Martinez JA, Hu FB, Gibney MJ \& Kearney J 1999 Physical inactivity, sedentary lifestyle and obesity in the European Union. International Journal of Obesity 23 1192-1201.

Mattes R 1990 Hunger ratings are not a valid proxy measure of reported food inatke in humans. Appetite 15 103-113.

Miller WC, Koceja DM \& Hamilton EJ 1997 A meta-analysis of the past 25 years of weight loss research using diet, exercise or diet plus exercise intervention. International Journal of Obesity 21 941-947.

National Audit Office 2001 Tackling Obesity in England. London: The Stationary Office.

Neary NM, Goldstone AP \& Bloom SR 2004 Appetite regulation: from the gut to the hypothalamus. Clinical Endocrinology 60 153-160.

Neary NM, Small CJ, Druce MR, Park AJ, Ellis SM, Semjonous NM, Dakin CL, Filipsson K, Wang F, Kent AS et al. 2005 Peptide YY3-36 and glucagon-like peptide-17-36 inhibit food intake additively. Endocrinology 146 5120-5127.

O'Connor AM, Pola S, Ward BM, Fillmore D, Buchanan KD \& Kirwan JP 2006 The gastroenteroinsular response to glucose ingestion during postexercise recovery. American Journal of Physiology, Endocrinology and Metabolism 290 E1155-E1161.

Patterson M, Murphy KG, le Roux CW, Ghatei MA \& Bloom SR 2005 Characterization of ghrelin-like immunoreactivity in human plasma. Journal of Clinical Endocrinology and Metabolism 90 2205-2211.

Robertson MD, Currie JM, Morgan LM, Jewell DP \& Frayn KN 2003 Prior short-term consumption of resistant starch enhances postprandial insulin sensitivity in healthy subjects. Diabetologia 46 659-665.
Rogers PJ 1993 The investigation of human eating behaviour. In Human Psychopharmacology, Measures and Methods, pp 123-142. Eds I Hindmarch \& PD Stonier. Chichester: John Wiley and Sons Ltd.

Schmidt A, Maier C, Schaller G, Nowothy P, Bayerle-Eder M, Buranyi B, Luger A \& Woizt M 2004 Acute exercise has no effect on ghrelin plasma concentrations. Hormone and Metabolic Research 36 174-177.

van Strien T, Frijters JER, Bergers GPA \& Defares PB 1986 The Dutch eating behavior questionnaire (DEBQ) for assessment of restrained, emotional, and external eating behavior. International Journal of Eating Disorders 5 259-315.

Sullivan SN, Champion MD, Christofides ND, Adrian TE \& Bloom SR 1984 Gastrointestinal regulatory peptide responses in long-distance runners. Physician and Sportsmedicine 12 77-82.

Tsofliou F, Pitsiladis YP, Malkova D, Wallace AM \& Lean ME 2003 Moderate physical activity permits acute coupling between serum leptin and appetitesatiety measures in obese women. International Journal of Obesity and Related Metabolic Disorders 27 1332-1339.

Varo JJ, Martinez-Gonzalez MA, De Irala-Estevez J, Kearney J, Gibney M \& Martinez JA 2003 Distribution and determinants of sedentary lifestyles in the European union. International Journal of Epidemiology 32 138-146.

Westerterp-Plantenga MS, Verwegen CR, Ijedema MJ, Wijckmans NE \& Saris WH 1997 Acute effects of exercise or sauna on appetite in obese and nonobese men. Physiology Behavior 62 1345-1354.

World Health Organization 2003 Global strategy on diet, physical activity and health - obesity and overweight. Internet Communication.

Received in final form 20 February 2007

Accepted 23 February 2007

Made available online as an Accepted Preprint 23 February 2007 